Prostate. 2020 February ; 80(2): 133-145. doi:10.1002/pros.23925.

\title{
RELA is sufficient to mediate interleukin-1 repression of androgen receptor expression and activity in an LNCaP disease progression model
}

\author{
Shayna E. Thomas-Jardin ${ }^{\# 1}$, Haley Dahl ${ }^{\# 1}$, Mohammed S. Kanchwala² ${ }^{2}$ Freedom Ha, BS ${ }^{1}$, \\ Joan Jacob, BS ${ }^{1}$, Reshma Soundharrajan ${ }^{1}$, Monica Bautista, MS ${ }^{1}$, Afshan F. Nawas, PhD'1, \\ Dexter Robichaux ${ }^{1}$, Ragini Mistry ${ }^{1}$, Vanessa Anunobi, BS ${ }^{1}$, Chao Xing, PhD ${ }^{2,3,4}$, Nikki A. \\ Delk, PhD ${ }^{1}$ \\ ${ }^{1}$ Biological Sciences Department, The University of Texas at Dallas, Richardson, Texas \\ ${ }^{2}$ McDermott Center of Human Growth and Development, The University of Texas Southwestern \\ Medical Center, Dallas, Texas \\ ${ }^{3}$ Department of Bioinformatics, The University of Texas Southwestern Medical Center, Dallas, \\ Texas \\ ${ }^{4}$ Department of Clinical Sciences, The University of Texas Southwestern Medical Center, Dallas, \\ Texas \\ \# These authors contributed equally to this work.
}

\section{Abstract}

Background-The androgen receptor (AR) nuclear transcription factor is a therapeutic target for prostate cancer (PCa). Unfortunately, patients can develop resistance to AR-targeted therapies and progress to lethal disease, underscoring the importance of understanding the molecular mechanisms that underlie treatment resistance. Inflammation is implicated in PCa initiation and progression and we have previously reported that the inflammatory cytokine, interleukin-1 (IL-1), represses $A R$ messenger RNA (mRNA) levels and activity in AR-positive ( $\left.\mathrm{AR}^{+}\right) \mathrm{PCa}$ cell lines concomitant with the upregulation of prosurvival biomolecules. Thus, we contend that IL-1 can select for AR-independent, treatment-resistant PCa cells.

Methods-To begin to explore how IL-1 signaling leads to the repression of $A R$ mRNA levels, we performed comprehensive pathway analysis on our RNA sequencing data from IL-1-treated LNCaP PCa cells. Our pathway analysis predicted nuclear factor kappa B (NF- $\mathrm{kB}$ ) p65 subunit (RELA), a canonical IL-1 signal transducer, to be significantly active and potentially regulate many genes, including $A R$. We used small interfering RNA (siRNA) to silence the NF- $\kappa \mathrm{B}$ family of transcription factor subunits, RELA, RELB, $c-R E L, N F K B 1$, or $N F K B 2$, in IL-1-treated

Correspondence: Nikki A. Delk, Department of Biological Sciences, The University of Texas at Dallas, 800 West Campbell Road, FO-1, Richardson, TX 75080. nikki.delk@utdallas.edu.

CONFLICT OF INTERESTS

The authors declare that there are no conflict of interests.

SUPPORTING INFORMATION

Additional supporting information may be found online in the Supporting Information section. 
LNCaP, C4-2, and C4-2B PCa cell lines. C4-2 and C4-2B cell lines are castration-resistant LNCaP sublines and represent progression toward metastatic $\mathrm{PCa}$ disease, and we have previously shown that IL-1 represses AR mRNA levels in C4-2 and C4-2B cells.

Results-siRNA revealed that RELA alone is sufficient to mediate IL-1 repression of AR mRNA and AR activity. Intriguingly, while LNCaP cells are more sensitive to IL-1-mediated repression of AR than C4-2 and C4-2B cells, RELA siRNA led to a more striking derepression of $A R$ mRNA levels and AR activity in C4-2 and C4-2B cells than in LNCaP cells.

Conclusions-These data indicate that there are RELA-independent mechanisms that regulate IL-1-mediated AR repression in LNCaP cells and suggest that the switch to RELA-dependent IL-1 repression of $\mathrm{AR}$ in $\mathrm{C} 4-2$ and $\mathrm{C} 4-2 \mathrm{~B}$ cells reflects changes in epigenetic and transcriptional programs that evolve during $\mathrm{PCa}$ disease progression.

\section{Keywords}

androgen receptor; interleukin-1; prostate cancer; RELA

\section{1 | INTRODUCTION}

Androgen deprivation is used as a first-line therapy for prostate cancer (PCa) patients, but some patients will inevitably progress to androgen-independent PCa. ${ }^{1}$ Activating mutations, splice variation, or overexpression of AR can render AR ligand independent or functional under castrate levels of androgen. ${ }^{1}$ Therefore, patients that develop androgen independence are given antiandrogens that directly bind and prevent AR transactivation activity. ${ }^{1} \mathrm{PCa}$ tumors can, however, evolve antiandrogen resistance, leading to lethal disease. ${ }^{1}$ Antiandrogens can function as AR agonists resulting in treatment resistance ${ }^{1}$; but antiandrogen resistance and AR independence can also result from the emergence of $\mathrm{PCa}$ tumor cells with low or no $\mathrm{AR}\left(\mathrm{AR}^{\text {low/-}}\right)$ accumulation or activity. ${ }^{2}$

We and others have found that interleukin-1 (IL-1) represses AR levels and activity in PCa cells $^{3-7}$ and one group has shown that chronic IL-1 exposure reduces sensitivity to the antiandrogen, bicalutamide in the androgen-dependent LNCaP PCa cell line. ${ }^{5}$ While inflammation and IL-1 are associated with reduced AR levels or activity in benign prostatic hyperplasia ${ }^{7}$ and there is evidence that IL-1 inversely correlates with AR activity in metastatic PCa patient tissue, ${ }^{8}$ it is unknown if IL-1 is sufficient to drive AR independence or treatment resistance during $\mathrm{PCa}$ disease progression. We previously reported that concomitant with AR repression, IL-1 induces a suite of genes in LNCaP cells that mimic basal gene expression in AR-independent PCa cell lines, ${ }^{6}$ suggesting that IL-1 exposure could select for viable AR-independent PCa tumor cells. For example, we demonstrated that sequestosome-1 (p62), an autophagy and antioxidant protein from our gene suite, ${ }^{6}$ is required for cell survival in AR-independent $\mathrm{PCa}$ cell lines ${ }^{9}$ and others have recently discovered that $p 62$ overexpression can drive prostate cell tumor formation in vivo. ${ }^{10}$

To begin to understand how IL-1 drives AR independence, we evaluated IL-1 regulation of $A R$ repression across a disease progression cell line model using $\mathrm{LNCaP}, \mathrm{C} 4-2$, and $\mathrm{C} 4-2 \mathrm{~B}$ $\mathrm{PCa}$ cell lines. $\mathrm{LNCaP}$ is an androgen-dependent cell line originating from a $\mathrm{PCa}$ patient 
lymph node metastasis. LNCaP cells require androgen and AR activity for survival and do not form metastatic tumors in mice. ${ }^{11-13}$ The $\mathrm{C} 4-2$ and C4-2B PCa cell lines are LNCaP sublines isolated from a subcutaneous tumor (C4-2) in a castrated mouse that metastasized to bone (C4-2B) when regrafted in a castrated mouse. ${ }^{13}$ Thus, $\mathrm{C} 4-2$ and $\mathrm{C} 4-2 \mathrm{~B}$ cells represent progressive, metastatic, androgen-independent PCa disease. ${ }^{13}$ As with LNCaP cells, IL-1 represses AR levels in C4-2 and C4-2B cell lines ${ }^{4,6}$ and, thus, are relevant cell line models to begin to address IL-1 regulation of AR during disease progression.

Nuclear factor kappa B (NF- $\mathrm{BB}$ ) transcription factor is the canonical mediator of IL-1 signaling. ${ }^{14}$ The NF- $\kappa B$ transcription factor family is comprised of RELA (p65), RELB, cREL, NFKB1 (p105/p50), and NFKB2 (p100/p52). ${ }^{14}$ RELA, RELB, and c-REL contain DNA-binding and transactivation domains. ${ }^{14}$ NFKB1 and NFKB2 are processed from 105 and $100 \mathrm{kDa}$ proteins to 50 and $52 \mathrm{kDa}$ subunits, respectively, that bind DNA but lack transactivation domains. ${ }^{14}$ The NF- $\mathrm{kB}$ family members form homo- and heterodimers to induce or repress transcription, ${ }^{14}$ where the RELA/p50 heterodimer typically regulates gene expression in response to IL-1. ${ }^{14}$ Using RNA sequencing (RNA-seq) pathway analysis of IL-1-treated LNCaP cells, we identified several candidate transcriptional regulators of AR expression. Not surprisingly, our analysis identified RELA as one of the most significantly activated transcriptional regulators of AR expression in IL-1-treated cells predicted by ingenuity pathway analysis (IPA) $(z$ score $=5.58, P$ value: $1.6 \mathrm{E}-11)$ and we show that RELA can indeed mediate IL-1 repression of AR levels and AR activity. Using the LNCaP PCa cell line progression model, our results also suggest that RELA-dependent repression of AR evolves with PCa progression toward androgen independence.

\section{2 | MATERIALS AND METHODS}

\subsection{Cell culture}

LNCaP, C4-2, and C4-2B PCa cell lines were maintained in a $37^{\circ} \mathrm{C}, 5.0 \%(\mathrm{v} / \mathrm{v}) \mathrm{CO}_{2}$ growth chamber, and cultured in Dulbecco's modified Eagle's medium (DMEM) (1185-092; Gibco/ Thermo Fisher Scientific) supplemented with $10 \%$ (v/v) fetal bovine essence (fetal bovine serum alternative) (FBE, 3100-500; Seradigm), 0.4 mM L-glutamine (L-glut, 25030-081; Gibco/Invitrogen), and $10 \mathrm{U} / \mathrm{mL}$ penicillin G sodium and $10 \mathrm{mg} / \mathrm{mL}$ streptomycin sulfate (pen-strep, 15140-122; Gibco/Invitrogen).

\subsection{Cell treatments}

2.2.1 Interleukin-1—Vehicle control ( $0.1 \%$ bovine serum albumin [BSA] in $1 \times$ phosphate-buffered saline [PBS]), 0.5, 5, or $25 \mathrm{ng} / \mathrm{mL}$ IL-1a (1110-01A-10; Gold Bio) or IL-1 $\beta$ (1110-01B-10; Gold Bio) were added to DMEM/10\% FBE growth medium.

2.2.2 Gene silencing small interfering RNA—For each gene, we used pooled small interfering RNAs (siRNAs) from Dharmacon (pool of 4) or OriGene (pool of 3). The following siRNA concentrations were used: $70 \mathrm{nM}$ nontargeting siRNA (D-001206-13-05; Dharmacon), RELA siRNA (M-003533-02-0005; Dharmacon), NFKB1 siRNA (M-003520-01-0005; Dharmacon), or p62 siRNA (M-010230-00-0005; Dharmacon); 100 nM nontargeting siRNA, RELB siRNA (M-004767-02-0005; Dharmacon), $c$-REL siRNA 
(M-004768-01-0005; Dharmacon), or NFKB2 siRNA (M-003918-02-0005; Dharmacon); 70 nM nontargeting siRNA (SR30004; Origene) or RELA siRNA (SR321602; Origene). Cells were transfected with siRNA using siTran 1.0 transfection reagent (TT300003; Origene) added to cells in DMEM/10\% FBE growth medium for 1 day. siRNA-containing medium was then removed and replaced with fresh DMEM/10\% FBE plus vehicle control, IL-1a, or IL-1 $\beta$.

2.2.3 Serum starvation-After plating, cells were maintained in DMEM/2.5\% FBE for several days before replacing medium with DMEM/0\% FBE (serum starvation) or DMEM/10\% FBE (replete medium control) for 4 days with or without $10 \mathrm{nM}$ R1881.

\subsection{Cell counts}

Cells were fixed in $100 \%$ cold methanol. The nuclei were stained with DAPI ( $4^{\prime}, 6-$ diamidino-2-phenylindole) (10236276001; Roche Diagnostics) and the stained cells imaged and counted using the Cytation3 Cell Imaging Multi-Mode Reader (BioTek, Winooski, VT).

\subsection{Crystal violet staining}

Cells were fixed in $100 \%$ cold methanol at $-20^{\circ} \mathrm{C}$ for 30 minutes and stained with $0.25 \%$ crystal violet (AC212120250; Acros Organics) in 10\% methanol for 5 minutes at room temperature. Excess stain was washed off with deionized water.

\subsection{RNA isolation and reverse-transcription quantitative polymerase chain reaction}

Total RNA was extracted, reverse-transcribed, and analyzed by reverse-transcription quantitative polymerase chain reaction (RT-qPCR) as previously described. ${ }^{6}$ Primer sequences for genes of interest are listed below. Gene of interest cycle times (CTs) were normalized to the $\beta$-actin. Relative messenger RNA (mRNA) levels were calculated using the $2^{-\Delta \Delta C t}$ method. Primer sequences, $5^{\prime}$ to $3^{\prime}$ : androgen receptor $(A R)$, forward AAGACGCTTCTACCAGCTCA CCAA, reverse TCCCAGAAAGGATCTTGGGCACTT; beta actin ( $\beta$-actin), forward GATGAGATTGGCATGGCTTT, reverse CACCTTCACCGGTCCAGTTT; prostate-specific antigen (PSA), forward CACCTGCTCGGGTGATTCTG, reverse ACTGCCCCATGACGTGA TAC; sequestosome-1 ( $p 62$ ), forward AAATGGGTCCACCAG GAAACTGGA, reverse TCAACTTCAATGCCCAGAGGGCTA; mitochondrial superoxide dismutase 2 (SOD2), forward GGCCTACGTGAA CAACCTGA, reverse GTTCTCCACCACCGTTAGGG; $R E L A$, forward TGAACCAGGGCATACCTGTG, reverse CCCCTGTCACTAGGC GAGTT; $N F K B 1$, forward TGATCCATATTTGGGAAGGCCTGA, reverse GTATGGGCCATCTGTTGGCAG; NFKB2, forward CCTAA GCAGAGAGGCTTCCG, reverse TCTTTCGGCCCTTCTCACTG; RELB, forward AGCTCTACTTGCTCTGCGAC, reverse AACACAATGG CAATCTGGCG; $c-R E L$, forward ACAGCACAGACAACAACCGA, reverse AGTAGCCGTCTCTGCAGTCT.

\subsection{RNA-seq analysis}

Pathway analysis was conducted using Qiagen's IPA tool (http://www.qiagen.com/ ingenuity). RNA-seq data sets used for this study are available at GEO NCBI, accession no. 
GSE105088. LNCaP samples treated with vehicle control or IL-1 $\beta$ were considered and 3658 differentially expressed genes with $\log _{2}$ counts per million (CPM) $\geq 0$, absolute $\log _{2}$ fold change (FC) $>0.6$, and false discovery rate (FDR) $\leq 0.05$ were considered for further downstream analysis.

\section{7| Western blot analysis}

Western blot analysis was done as previously described. ${ }^{6}$ Briefly, primary and secondary antibodies were diluted in 2.5\% BSA in 1× Tris-buffered saline with Tween 20 (TBST). Protein blot bands were visualized using SuperSignal West Femto Maximum Sensitivity Substrate (34095; Thermo Fisher Scientific) or Clarity Western ECL Substrate (1705061; Bio-Rad) and imaged using the Amersham Imager 600 (GE, Marlborough, MA).

2.7.1 Primary antibodies_AR (D6F11; Cell Signaling), p62 (H00008878-M01; Abnova), SOD2 (AM7579a; Abgent), $\beta$-actin (sc-69879; Santa Cruz), RELA (6956S; Cell Signaling), NFKB1 (3035S; Cell Signaling), PSA (5365S; Cell Signaling), or c-REL (4727T; Cell Signaling).

2.7.2 Secondary antibodies-Sheep antimouse (515-035-062; Jackson ImmunoResearch Laboratories), goat antirabbit (PAB10822; Abnova).

2.7.3 Densitometry-Western blot densitometry for protein bands was performed using Image J (National Institutes of Health, Bethesda, MD). Protein bands were first normalized to $\beta$-actin loading control and then normalized to the treatment control.

\section{8 | Immunofluorescence}

Cells were fixed and permeabilized with $100 \%$ methanol at $-20^{\circ} \mathrm{C}$ for 30 minutes. Fixed cells were blocked with $2.5 \%$ BSA in $1 \times$ PBS at room temperature for at least 30 minutes. Antibodies were diluted in $2.5 \%$ BSA in $1 \times$ PBS.

\subsubsection{Primary antibody—AR (D6F11; Cell Signaling).}

2.8.2 Secondary antibody-Alexafluor 568, goat anti-rabbit (A11061; Invitrogen). Nuclei were stained with DAPI (10236276001; Roche Diagnostics). Immunostained cells were imaged at $\times 20$ magnification using the Nikon Eclipse Ti fluorescence microscope and Nikon NIS Elements software (Nikon, Melville, NY).

\section{9 | Statistical analysis}

Statistical significance was determined using unpaired Student's t test. $P \leq .05$ is considered statistically significant. "NS" indicates no statistical significance. Error bars indicate \pm standard deviation (SD); $\mathrm{n} \geq 3$ biological replicates. Experiments were repeated at least three times and representative data are shown. 


\section{3 | RESULTS}

\subsection{RNA-seq pathway analysis reveals RELA as a potential regulator of $A R$ expression}

We previously performed RNA-seq on the LNCaP PCa cell line treated with IL-1 $\beta$ and found that AR and AR target genes are downregulated. ${ }^{6}$ Here, we performed upstream regulator analysis using IPA on the vehicle control vs IL- $1 \beta$-treated LNCaP data sets and identified RELA as a significantly active transcriptional regulator of $A R(z$ score $=5.58, P$ value: 1.6E-11). Figure 1 shows selected RELA interactors from our IPA analysis. A complete list of RELA interactors identified based on IPA for IL-1 $\beta$-treated LNCaP cells and their relationships can be found in Table S1. It is worth noting that IPA's knowledge base indicates RELA to be a positive regulator of $A R$ expression, which is inconsistent (indicated by the yellow arrow between RELA and AR, Figure 1) with our RNA-seq data that indicate that IL- $1 \beta$ represses AR mRNA levels in LNCaP cells. Therefore, we set out to experimentally test the relationship between RELA activity and $A R$ expression in our model. To do so, we silenced RELA in IL-1-treated LNCaP cells and used SOD2 expression as a positive control for RELA activity.

\subsection{LNCaP, C4-2, and C4-2B cell lines show differential sensitivity to IL-1}

Before embarking on our investigation of RELA regulation of $A R$ expression in the $\mathrm{LNCaP}$ cells, we had observed that LNCaP cells are more sensitive to IL-1 signaling than C4-2 or C4-2B cells. For example, we find that IL-1-treated LNCaP cells show greater SOD2 upregulation and AR repression than C4-2 or C4-2B cells. Based on RT-qPCR, $25 \mathrm{ng} / \mathrm{mL}$ IL-1a- or IL-1 $\beta$-induced SOD2 mRNA levels $\sim 18$-fold in LNCaP cells vs $\sim 6$-fold in C4-2B cells (Figure $2 \mathrm{~A}$ ) and based on Western blot analysis, $25 \mathrm{ng} / \mathrm{mL} \mathrm{IL-1} \mathrm{a}$ - or IL-1 $\beta$-induced SOD2 protein accumulation $\sim 5$-fold in LNCaP cells vs $\sim 3$-fold in C4-2 and C4-2B cells (Figure 2B). Furthermore, $25 \mathrm{ng} / \mathrm{mL}$ IL-1a- or IL-1 $\beta$-repressed AR mRNA levels $\sim 5$-fold in LNCaP cells vs $\sim 3$-fold in C4-2 or $\sim 2$-fold in C4-2B cells (Figure $2 \mathrm{~A}$ ). Similarly, Western blot analysis shows that $25 \mathrm{ng} / \mathrm{mL}$ IL-1a- or IL-1 $\beta$-repressed AR protein accumulation $\sim 6$ fold in LNCaP cells vs $\sim 4$-fold in C4-2 cells or $\sim 2$-fold in C4-2B cells (Figure 2B).

Interestingly, while IL-1 receptor (IL-1R1) mRNA levels are elevated in C4-2 and C4-2B cells and RELA mRNA and protein levels are similar across LNCaP, C4-2, and C4-2B cell lines, basal NFKB1 mRNA and p50 protein levels are lower in C4-2 and C4-2B cells than in LNCaP cells and IL-1-mediated induction of NFKB1 mRNA and p50 protein levels is not as robust in C4-2 or C4-2B cells as in LNCaP cells (Figure 2A,B). Given that canonical IL-1 signaling is mediated via the RELA/p50 heterodimer, ${ }^{14}$ the lower $N F K B 1$ mRNA and p50 protein levels might underlie C4-2- and C4-2B-reduced sensitivity to IL-1.

In addition to reduced sensitivity to IL-1 modulation of target mRNA and protein levels, C4-2 and C4-2B cells are less sensitive to IL-1-induced cytotoxicity. LNCaP, C4-2, and C4-2B cells were grown in $25 \mathrm{ng} / \mathrm{mL}$ IL-1a or IL- $1 \beta$ for 1,3 , or 5 days and the cell number was recorded (Figure $2 \mathrm{C}$ ). Cells were also visualized on day 5 using crystal violet stain (Figure 2C). C4-2 and C4-2B cells show faster growth rate than $\mathrm{LNCaP}$ cells in both vehicle and IL-1 treatment conditions; but when comparing cytotoxicity in IL-1, C4-2, and C4-2B cells show $\sim 14 \%$ to $23 \%$ reduction in cell numbers on day 5 , while $\mathrm{LNCaP}$ cells show $\sim 58 \%$ 
reduction (Figure 2C). Thus, compared with LNCaP cells, C4-2 and C4-2B cells have reduced sensitivity to IL-1.

As stated earlier, C4-2 and C4-2B cell lines are less dependent on androgen than LNCaP cells. ${ }^{13}$ For example, compared with LNCaP cells, C4-2 and C4-2B cells have reduced sensitivity to growth arrest under serum-free growth conditions (Figure S1). Interestingly, relative to LNCaP cells, C-42 and C4-2B cells have reduced basal mRNA and protein levels of the AR target gene, PSA (Figure 2), but have higher basal levels of the AR target gene, kallikrein (KLK2) (Figure S3A), indicating that the regulation of AR target genes is altered in C4-2 and C4-2B cells. Taken together, cell response to IL-1 signaling may evolve with androgen, including IL-1-RELA regulation of AR levels and activity, which we investigate below.

\subsection{RELA mediates IL-1 repression of AR levels and activity differentially in LNCaP vs C4-2 and C4-2B cells}

To determine if RELA mediates IL-1 repression of AR, we siRNA-silenced RELA in IL-1treated LNCaP, C4-2, or C4-2B cells and analyzed AR mRNA levels and protein accumulation. We also analyzed PSA or KLK2 mRNA and/or protein levels as surrogates for AR transcriptional activity and we immunostained cells for AR nuclear accumulation. LNCaP, C4-2, and C4-2B cells were treated with vehicle control, $25 \mathrm{ng} / \mathrm{mL} \mathrm{IL-1a}$, or 25 $\mathrm{ng} / \mathrm{mL}$ IL- $1 \beta$ in the presence of nontargeting control siRNA or two different pools of RELA siRNA. RELA siRNA was sufficient to attenuate IL-1 repression of AR, PSA, and KLK2 mRNA and/or protein (Figures 3, S2, and S3B) and AR nuclear accumulation (Figure 4) in C4-2 and C4-2B cells treated with $25 \mathrm{ng} / \mathrm{mL}$ IL-1. However, RELA siRNA was not sufficient to attenuate IL-1 repression of AR or showed only a slight effect on PSA or KLK mRNA and/or protein in LNCaP cells treated with $25 \mathrm{ng} / \mathrm{mL}$ IL-1 (data not shown). Given the enhanced sensitivity of LNCaP cells to IL-1, we instead silenced RELA in LNCaP cells treated with a lower IL-1 concentration $(0.5 \mathrm{ng} / \mathrm{mL})$ and found that $R E L A$ siRNA was sufficient to attenuate IL-1 repression of AR, PSA, and KLK2 mRNA and/or protein levels; however, the LNCaP response to RELA siRNA was not consistent or as robust as for the C4-2 or C4-2B cell lines (Figures 3, S2, and S3, data not shown). As a positive control for $R E L A$ siRNA efficacy, RELA siRNA was sufficient to attenuate SOD2 mRNA and protein levels in IL-1-treated LNCaP, C4-2, and C4-2B cells (Figures 3 and S2) and as a negative control for RELA siRNA specificity, RELA siRNA did not affect KEAP1 mRNA levels (Figure S2). Taken together, our data indicate that RELA mediates IL-1 repression of AR in C4-2 or C4-2B cells and to a lesser extent in LNCaP cells.

\subsection{IL-1 repression of AR levels or activity is specific to the RELA NF- $x B$ family member}

Given that the RELA/p50 heterodimer mediates canonical IL-1 signaling ${ }^{14}$ and that $R E L A$ siRNA downregulates $N F K B 1 \mathrm{mRNA}$ and p50 protein in IL-1-treated cells (Figures 3 and S2), we expected that loss of NFKB1 would also attenuate IL-1 repression of AR levels and activity. NFKB1 siRNA alone was not sufficient to attenuate IL-1 repression of AR or PSA levels, nor sufficient to block IL-1 induction of SOD2 mRNA or protein levels in LNCaP, C4-2, or C4-2B cells (Figure 5). Similar results were obtained for $R E L B, c-R E L$, and 
NFKB2 siRNA (Figures S4-S6). Taken together, our data suggest that RELA is the NF- $\kappa B$ family member that is necessary and sufficient for IL-1-mediated AR repression.

\section{5 | p62 does not mediate IL-1 repression of AR levels or activity}

IL-1 upregulates p62 accumulation in PCa cell lines, ${ }^{4,6}$ p62 is an IL-1-RELA target gene (Figure 3), and p62 is a known mediator of IL-1-induced NF- $\mathrm{kB}$ activation. ${ }^{15-17}$ To investigate if p62 mediates IL-1-RELA repression of AR, IL-1-treated LNCaP, C4-2, or C4-2B cells were transfected with $p 62$ siRNA. p62 siRNA was not sufficient to attenuate IL-1 repression of AR or PSA levels or to block IL-1 induction of SOD2 levels in LNCaP, C4-2, or C4-2B cells (Figure 6). Thus, while IL-1-RELA signaling induces p62 mRNA and protein accumulation, p62 does not appear to be necessary for IL-1-RELA repression of AR levels or activity in LNCaP, C4-2, or C4-2B cells. Interestingly, p62 siRNA consistently upregulates PSA mRNA and protein in C4-2 and C4-2B cells under basal growth conditions, but $p 62$ siRNA does not affect PSA or AR levels or AR activity in the presence of IL-1 (Figure 6). Thus, p62 function includes PSA repression, but independent of IL-1 signaling.

\section{4 | DISCUSSION}

\section{1 | IL-1-RELA represses AR mRNA and protein levels}

$R E L A$ overexpression in LNCaP cells has been shown to induce $A R$ mRNA accumulation and AR nuclear accumulation ${ }^{18,19}$; conversely, cosilencing of $R E L A$ and $p 50$ reduced AR protein levels in LNCaP cells. ${ }^{18}$ Another study found that $p 52$ overexpression, but not $R E L A$ overexpression, induces AR nuclear accumulation and activity in LNCaP cells, while neither $p 52$ nor $R E L A$ overexpression affected AR mRNA levels. ${ }^{20}$ Finally, counter to AR activation by $R E L A$ or $p 52$ overexpression, $c-R E L$ overexpression was shown to block $\mathrm{AR}$ activity in LNCaP cells. ${ }^{21}$ Thus, NF- $\mathrm{KB}$ regulation of AR expression and activity is complex and context specific.

Notably, the studies described above mimic constitutive NF- $\kappa$ B activity through forced overexpression. We instead, silenced basal or IL-1-induced NF- $\mathrm{kB}$ activity in LNCaP, C4-2, or $\mathrm{C} 4-2 \mathrm{~B}$ cells. We did not observe a change in AR levels or AR activity under basal growth conditions by any NF- $\kappa B$ family member and using two different pools of oligos. Only RELA repressed AR levels and activity, and only in the presence of IL-1. RELA is the canonical mediator of IL-1-induced NF- $\kappa B$ signaling ${ }^{14}$ so it is not surprising that RELA would mediate IL-1 repression of AR levels and activity.

Like IL-1, tumor necrosis factor alpha (TNF-a) signals through RELA/p50. ${ }^{14}$ TNF-a was shown to repress AR expression in a NF- $\kappa \mathrm{B}$-dependent ${ }^{22}$ or RELA-dependent manner ${ }^{23}$ in LNCaP cells. As we observed for IL-1-treated cells, siRNA loss of NFKB1 did not affect $A R$ mRNA levels in TNF-a-treated cells ${ }^{23}$; however, p50 did bind the AR promoter in TNFa-treated cells, along with RELA and the HDAC and NCoR corepressors. ${ }^{23}$ It remains to be investigated if IL-1 signaling represses $A R$ expression through a signaling mechanism similar to TNF- $a$ and/or if RELA indirectly, for example, through microRNAs, downregulates $A R$ mRNA levels. Indeed, it has been shown that TNF-a reduces AR mRNA stability post-transcriptionally. ${ }^{24}$ RELA can also form homodimers to regulate 
transcription ${ }^{14}$; thus, it is also possible that RELA mediates IL-1 repression of AR levels and activity independent of $\mathrm{p} 50$.

\subsection{IL-1-RELA signaling differs among androgen-dependent LNCaP vs androgen- independent C4-2 and C4-2B cells}

We confirmed that the $\mathrm{C} 4-2$ and $\mathrm{C} 4-2 \mathrm{~B}$ cell lines are less dependent on androgen than the LNCaP cell line and we discovered that C4-2 and C4-2B cells are less sensitive to IL-1 signaling than LNCaP cells, yet C4-2 and C4-2B cells are more dependent on RELAmediated repression of AR levels and activity in response to IL-1 signaling. Interestingly, C4-2 and C4-2B are also less sensitive to TNF- $a$ than LNCaP cells, and reduced sensitivity is, in part, dependent on reduced basal levels of the TNF- $\alpha$ receptor-associated protein, TRADD $^{22}$ and we find that $\mathrm{C} 4-2$ and C4-2B cells have reduced basal levels of the NF- $\kappa \mathrm{B}$ p50 transcription factor subunit which likely contributes to reduced IL-1 and TNF-a sensitivity. Taken together, our and other published results suggest that during PCa disease progression, cell response to inflammation evolves. To better understand the molecular mechanisms underlying IL-1-RELA signaling in AR-dependent vs AR-independent PCa cells, it will be informative to identify the differences in cofactors, chromatin markers, and chromatin structure at the AR locus in IL-1-treated LNCaP, C4-2, and C4-2B cells.

Our results suggest that changes can occur in IL-1-RELA signaling during PCa disease progression that could promote AR independence and resistance to AR-targeting antiandrogens by selecting for cells that adapt to survive with low or no AR accumulation or activity. For example, while IL-1 is a cytotoxic inflammatory cytokine, the surviving subpopulation upregulates prosurvival proteins and pathways, such as IL-1-RELA-induced, p62, ${ }^{4,6}$ which might compensate for the loss of AR accumulation or activity. Furthermore, studies show that inflammation, including IL-1 accumulation, inversely correlates with AR levels or activity in PCa disease progression. ${ }^{7,8}$ Interestingly, while IL-1 has been found to inversely correlate with AR levels or activity, constitutive RELA accumulation appears to positively correlate with biochemical relapse, ${ }^{25,26}$ presumably due to AR activity, in $\mathrm{PCa}$ disease progression. In this context, RELA accumulation may reflect evolved constitutive RELA signaling that is independent of cell response to exogenous IL-1.

\section{3 p62 silencing does not prevent IL-1-RELA repression of AR level or activity}

Using p62 siRNA, we were able to reduce $p 62$ levels to at least the levels observed in the $R E L A$ knockdowns of IL-1-treated cells and, thus, we would have expected to detect some attenuation of IL-1-induced $A R$ repression in $p 62$-silenced cells if p62 were required. $p 62$ silencing did not affect $A R$ mRNA levels in IL-1-treated cells. Likewise, the RELA target gene, $S O D 2$, did not change in p62-silenced IL-1-treated cells, further supporting that RELA can function independently of p62 in response to IL-1. Our results were unexpected given that p62 has been shown to mediate IL-1 activation of NF- $\mathrm{BB}$ activity in HepG and HEK293 cells $^{15-17}$; but our results may reflect underlying differences in cell lines and/or treatment conditions.

Interestingly, p62 silencing did significantly upregulate PSA mRNA levels in C4-2 and $\mathrm{C} 4-2 \mathrm{~B}$ cells under basal growth conditions, suggesting the p62 promotes the repression of 
basal PSA levels and/ or basal AR activity. While we did not detect an effect on PSA mRNA or protein levels in LNCaP cells transfected with $p 62$ siRNA, the sensitivity of RNA-seq does reveal that $p 62$ siRNA upregulates $P S A$ mRNA levels in LNCaP cells (data not shown). Thus, as observed for IL-1-RELA signaling, LNCaP, C4-2, and C4-2B cells may have differential response to $\mathrm{p} 62$ signaling that correlates with castration resistance.

Our RELA siRNA data indicate that RELA mediates IL-1 induction of p62 mRNA and protein accumulation. RELA siRNA, however, had no effect on p62 levels under basal growth conditions. Thus, p62 repression of basal PSA levels and/or basal AR activity is independent of RELA activity. The molecular mechanism and functional significance of p62 repression of $P S A$ is unknown but should be explored given that PSA is prognostic for $\mathrm{PCa}$ diagnosis and treatment response. ${ }^{27}$

\section{5 | CONCLUSION}

Cumulative evidence suggests that IL-1 promotes androgen and AR independence in PCa. Elevated IL-1 is associated with disease progression, ${ }^{8,28} \mathrm{IL}-1$ accumulation inversely correlates with AR activity in PCa patient tissue, ${ }^{8}$ IL-1 signaling downregulates AR levels and activity, ${ }^{3-7}$ and chronic IL-1 exposure promotes antiandrogen resistance. ${ }^{5}$ Androgen deprivation can induce tumor microenvironment inflammation, including IL-1 accumulation, by promoting immune cell infiltration and PCa cell IL-1 secretion. ${ }^{29}$ Thus IL-1 can select for treatment-resistant PCa cells, for example, following therapy by selecting for PCa cells that adapt to low or no AR accumulation or activity.

In the era of antiandrogen use, there has been an increase in castration-resistant patients with low or no AR activity ${ }^{2}$; the functional or correlative significance of IL-1-RELA signaling has yet to be determined in these patients. Our data shows that IL-1-induced RELA activity can attenuate AR accumulation and activity in PCa cells and, thus, further exploration and clarification of IL-1-RELA signaling in PCa disease progression and treatment resistance is warranted to identify alternative therapeutic targets to AR.

\section{Supplementary Material}

Refer to Web version on PubMed Central for supplementary material.

\section{ACKNOWLEDGMENTS}

For their advice and support throughout this process, we would like to thank all the members of the labs of Drs. Nikki A. Delk and Chao Xing. We would also like to acknowledge financial support for the Delk lab from the University of Texas at Dallas and financial support from the National Institutes of Health (NIH/NCI R21CA175798 (NAD); NIH/NCI K01CA160602 (NAD); NIH UL1TR001105 (CX)).

Funding information

National Institutes of Health, Grant/Award Number: UL1TR001105; National Cancer Institute, Grant/Award Numbers: K01CA160602, R21CA175798; University of Texas System 


\section{REFERENCES}

1. Nakazawa M, Paller C, Kyprianou N. Mechanisms of therapeutic resistance in prostate cancer. Curr Oncol Rep. 2017;19:13. [PubMed: 28229393]

2. Bluemn EG, Coleman IM, Lucas JM, et al. Androgen receptor pathway-independent prostate cancer is sustained through FGF signaling. Cancer Cell. 2017;32:474-489. [PubMed: 29017058]

3. Culig Z, Hobisch A, Herold M, et al. Interleukin $1 \beta$ mediates the modulatory effects of monocytes on LNCaP human prostate cancer cells. Br J Cancer. 1998;78:1004-1011. [PubMed: 9792142]

4. Chang MA, Patel V, Gwede M, et al. IL-1 $\beta$ induces p62/SQSTM1 and represses androgen receptor expression in prostate cancer cells. J Cell Biochem. 2014;115:2188-2197. [PubMed: 25103771]

5. Staverosky JA, Zhu XH, Ha S, Logan SK. Anti-androgen resistance in prostate cancer cells chronically induced by interleukin-1 $\beta$. Am J Clin Exp Urol. 2013;1:53-65. [PubMed: 25374900]

6. Thomas-Jardin SE, Kanchwala MS, Jacob J, et al. Identification of an IL-1-induced gene expression pattern in $\mathrm{AR}^{+} \mathrm{PCa}$ cells that mimics the molecular phenotype of $\mathrm{AR}^{-} \mathrm{PCa}$ cells. Prostate. 2018;78:595-606. [PubMed: 29527701]

7. Zhang B, Kwon OJ, Henry G, et al. Non-cell-autonomous regulation of prostate epithelial homeostasis by androgen receptor. Mol Cell. 2016;63:976-989. [PubMed: 27594448]

8. Liu Q, Russell MR, Shahriari K, et al. Interleukin-1 promotes skeletal colonization and progression of metastatic prostate cancer cells with neuroendocrine features. Cancer Res. 2013;73:3297-3305. [PubMed: 23536554]

9. Chang MA, Morgado M, Warren CR, Hinton CV, Farach-Carson MC, Delk NA. p62/SQSTM1 is required for cell survival of apoptosisresistant bone metastatic prostate cancer cell lines. Prostate. 2014;74:149-163. [PubMed: 24122957]

10. Wang L, Kim D, Wise JT, Shi X, Zhang Z, DiPaola RS. Retracted: p62 as a therapeutic target for inhibition of autophagy in prostate cancer. Prostate. 2018;78:390-400. [PubMed: 29368435]

11. Horoszewicz JS, Leong SS, Kawinski E, et al. LNCap model of human prostatic carcinoma. Cancer Res. 1983;43:1809-1818. [PubMed: 6831420]

12. Compagno D, Merle C, Morin A, et al. SIRNA-directed in vivo silencing of androgen receptor inhibits the growth of castration-resistant prostate carcinomas. PLOS One. 2007;2:e1006. [PubMed: 17925854]

13. Thalmann GN, Anezinis PE, Chang SM, et al. Androgen-independent cancer progression and bone metastasis in the LNCaP model of human prostate cancer. Cancer Res. 1994;54:2577-2581. [PubMed: 8168083]

14. Oeckinghaus A, Ghosh S. The NF- $\mathrm{BB}$ family of transcription factors and its regulation. Cold Spring Harbor Perspect Biol. 2009;1:a000034.

15. Tarantino N, Tinevez JY, Crowell EF, et al. TNF and IL-1 exhibit distinct ubiquitin requirements for inducing NEMO-IKK supramolecular structures. J Cell Biol. 2014;204:231-245. [PubMed: 24446482]

16. Zotti T, Scudiero I, Settembre P, et al. TRAF6-mediated ubiquitination of NEMO requires p62/ sequestosome-1. Mol Immunol. 2014;58: 27-31. 10.1016/j.molimm.2013.10.015 [PubMed: 24270048]

17. Sanz L, Diaz-Meco MT, Nakano H, Moscat J. The atypical PKC-interacting protein p62 channels NF-kappaB activation by the IL-1-TRAF6 pathway. EMBO J. 2000;19:1576-1586. [PubMed: 10747026]

18. Zhang L, Altuwaijri S, Deng F, et al. NF- $\kappa$ B regulates androgen receptor expression and prostate cancer growth. Am J Pathol. 2009;175:489-499. 10.2353/ajpath.2009.080727 [PubMed: 19628766]

19. Jin RJ, Lho Y, Connelly L, et al. The nuclear factor- $\kappa B$ pathway controls the progression of prostate cancer to androgen-independent growth. Cancer Res. 2008;68:6762-6769. 10.1158/0008-5472.CAN-08-0107 [PubMed: 18701501]

20. Nadiminty N, Lou W, Sun M, et al. Aberrant activation of the androgen receptor by NF- $\mathrm{B} 2 / \mathrm{p} 52$ in prostate cancer cells. Cancer Res. 2010;70:3309-3319. 10.1158/0008-5472.CAN-09-3703 [PubMed: 20388792] 
21. Mukhopadhyay NK, Ferdinand AS, Mukhopadhyay L, et al. Unraveling androgen receptor interactomes by an array-based method: discovery of proto-oncoprotein c-Rel as a negative regulator of androgen receptor. Exp Cell Res. 2006;312:3782-3795. 10.1016/j.yexcr.2006.07.017 [PubMed: 17011549]

22. Wang D, Montgomery RB, Schmidt LJ, et al. Reduced tumor necrosis factor receptor-associated death domain expression is associated with prostate cancer progression. Cancer Res. 2009;69:9448-9456. 10.1158/0008-5472.CAN-09-1903 [PubMed: 19934328]

23. Ko S, Shi L, Kim S, Song CS, Chatterjee B. Interplay of nuclear factor- $\kappa$ B and B-myb in the negative regulation of androgen receptor expression by tumor necrosis factor a. Mol Endocrinol. 2008;22:273-286. [PubMed: 17975021]

24. Mizokami A, Gotoh A, Yamada H, Keller ET, Matsumoto T. Tumor necrosis factor-a represses androgen sensitivity in the LNCaP prostate cancer cell line. J Urol. 2000;164:800-805. [PubMed: 10953159]

25. Domingo-Domenech J, Mellado B, Ferrer B, et al. Activation of nuclear factor- $\kappa \mathrm{B}$ in human prostate carcinogenesis and association to biochemical relapse. Br J Cancer. 2005;93: 1285-1294. [PubMed: 16278667]

26. Ross JS, Kallakury BVS, Sheehan CE, et al. Expression of nuclear factor- $\kappa$ B and I $\kappa$ B proteins in prostatic adenocarcinomas. Clin Cancer Res. 2004;10:2466-2472. [PubMed: 15073126]

27. Terada N, Akamatsu S, Kobayashi T, Inoue T, Ogawa O, Antonarakis ES. Prognostic and predictive biomarkers in prostate cancer: latest evidence and clinical implications. Ther Adv Med Oncol. 2017;9:565-573. [PubMed: 28794807]

28. Tazaki E, Shimizu N, Tanaka R, et al. Serum cytokine profiles in patients with prostate carcinoma. Exp Ther Med. 2011;2: 887-891. [PubMed: 22977593]

29. Shen YC, Ghasemzadeh A, Kochel CM, et al. Combining intratumoral Treg depletion with androgen deprivation therapy (ADT): preclinical activity in the Myc-CaP model. Prostate Cancer Prostatic Dis. 2018;21:113-125. [PubMed: 29203894] 


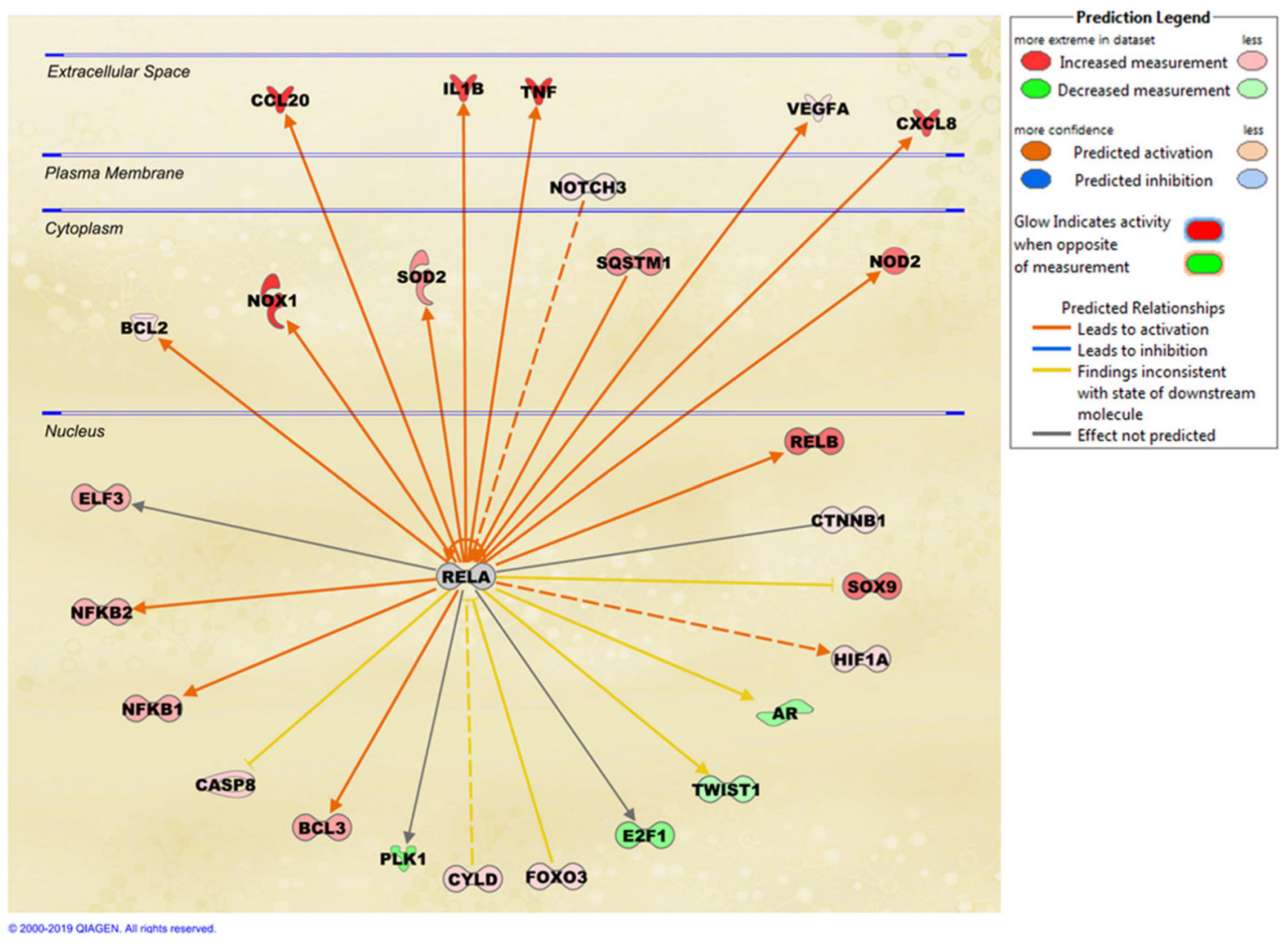

FIGURE 1.

RELA interactome. Upstream regulator analysis of IPA identified RELA as one of the most activated transcription factors (activation z score $=5.58$ ). Here we show selected interactome of RELA which has significant overlap ( $P$ value: $1.6 \mathrm{E}-11)$ with our gene set (GSE105088) of IL-1-induced genes in LNCaP. A complete list of proteins in this RELA interactome can be found in Table S1. Red color indicates the gene encoding the protein was significantly upregulated (IL-1-induced) in our gene set and green color indicates downregulation (IL-1inhibited). Orange color indicates predicted activation consistent with knowledge base and blue color indicates predicted inhibition, yellow color indicated inconsistent findings between our data and the knowledge base. Solid arrow indicates direct relationship and dotted line indicates indirect relationship. IPA knowledge base predicts that RELA activates AR expression in IL-1-treated cells which is inconsistent (yellow arrow) with our gene expression data (GSE105088). IL, interleukin; IPA, ingenuity pathway analysis [Color figure can be viewed at wileyonlinelibrary.com] 

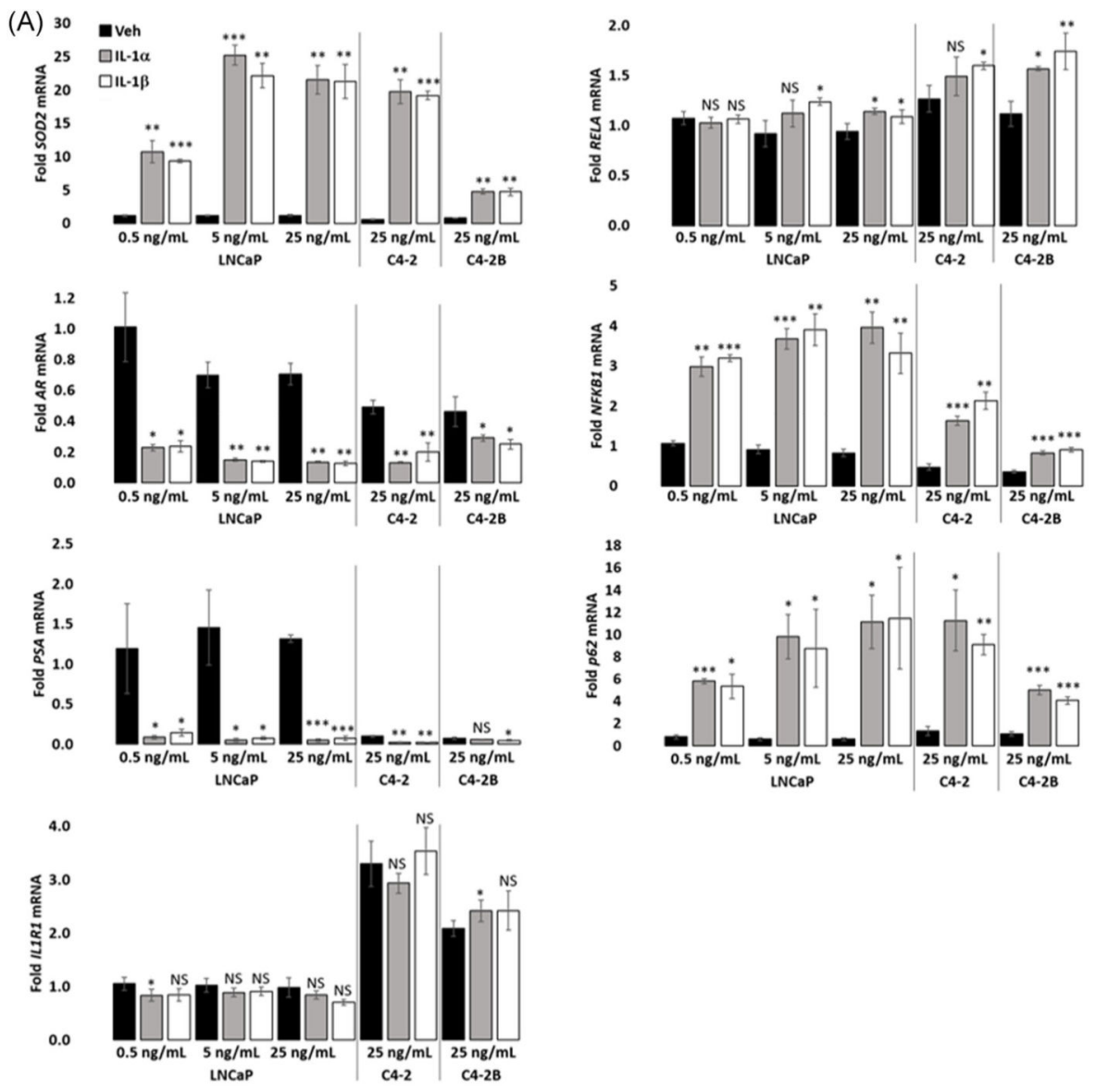

(B)

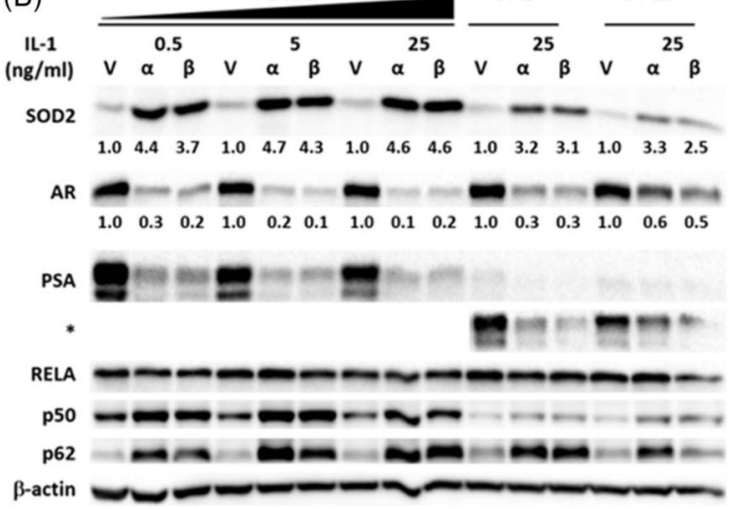

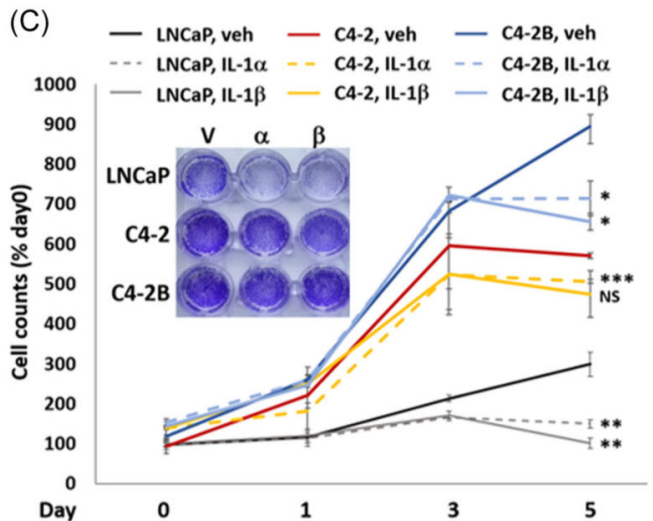

FIGURE 2.

The LNCaP series shows differential sensitivity to IL-1. A, RT-qPCR and B, Western blot analysis and densitometry were performed for LNCaP, C4-2, and C4-2B cells treated for 2 days with vehicle control (Veh, V), IL-1a, or IL-1 $\beta$. IL-1 upregulates SOD2, NFKB1(p50), and p62 levels and represses AR and PSA levels. RELA levels do not change. $I L-1 R 1$ mRNA levels are basal high, but NFKB1(p50) levels are basally low in C4-2 and C4-2B. C, LNCaP, C4-2, and C4-2B cells were treated with vehicle control (V), $25 \mathrm{ng} / \mathrm{mL}$ IL-1a, or 25 $\mathrm{ng} / \mathrm{mL}$ IL-1 $\beta$ for 0 to 5 days. Cells were stained with DAPI for cell counts or stained with 
crystal violet (inset image). $\mathrm{LNCaP}$ cells are more sensitive to IL-1 gene and protein regulation and cytotoxicity than $\mathrm{C} 4-2$ or $\mathrm{C} 4-2 \mathrm{~B}$ cells. mRNA fold change is normalized to the vehicle control for LNCaP $0.5 \mathrm{ng} / \mathrm{mL}$ IL-1 treatment for all cell lines and treatments. Cell counts were normalized to day 0 , vehicle control. Day 0 is the day before treatment. Error bars indicate $\pm \mathrm{SD}$ of three biological replicates: $* P \leq .05$, ** $P \leq .005$, *** $P \leq .0005$. AR, androgen receptor; DAPI, 4',6-diamidino-2-phenylindole; IL, interleukin; mRNA, messenger RNA; PSA, prostate-specific antigen; RT-qPCR, reverse-transcription quantitative polymerase chain reaction; $\mathrm{SD}$, standard deviation; SOD2, superoxide dismutase 2 [Color figure can be viewed at wileyonlinelibrary.com] 

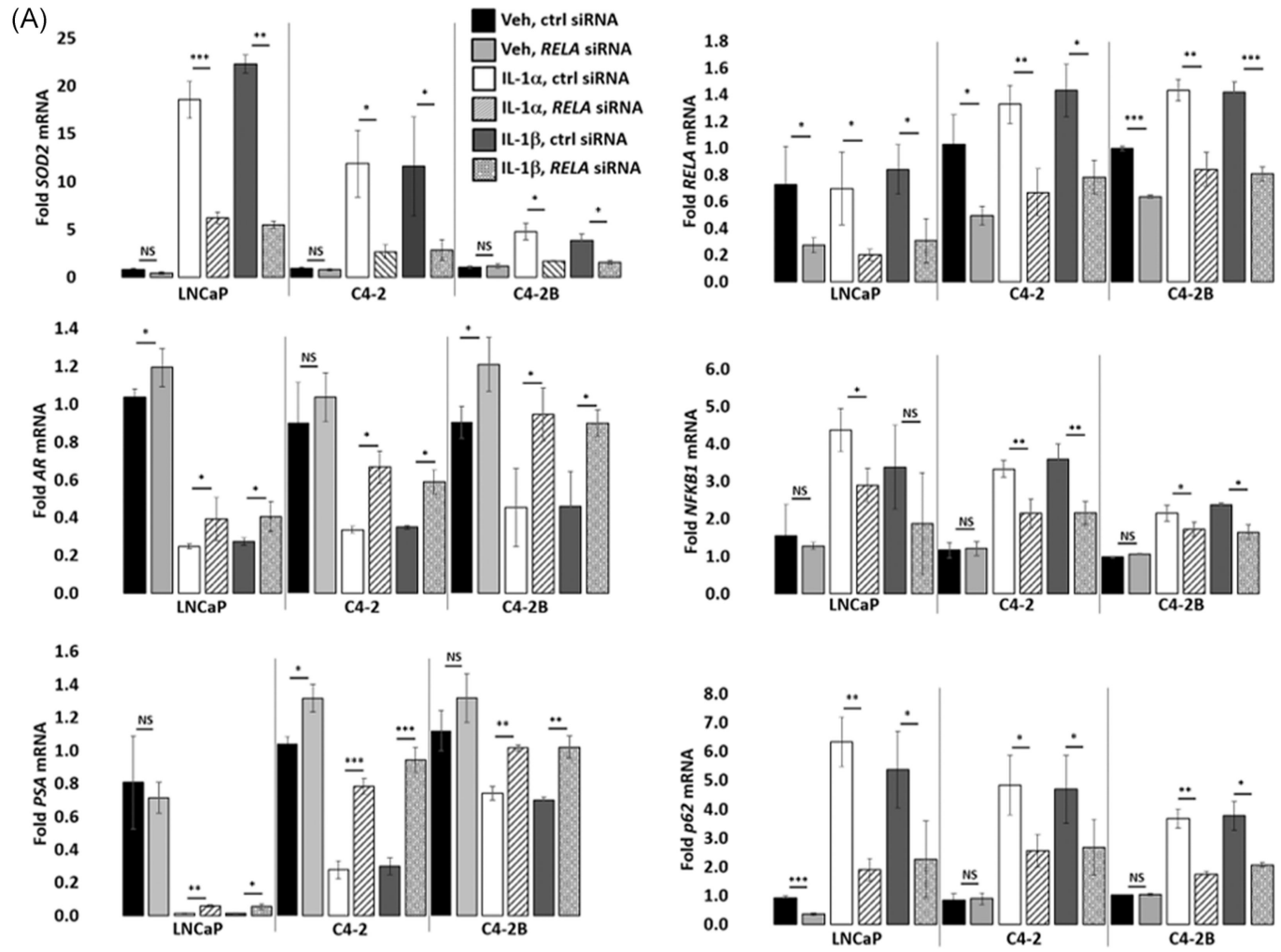

(B)
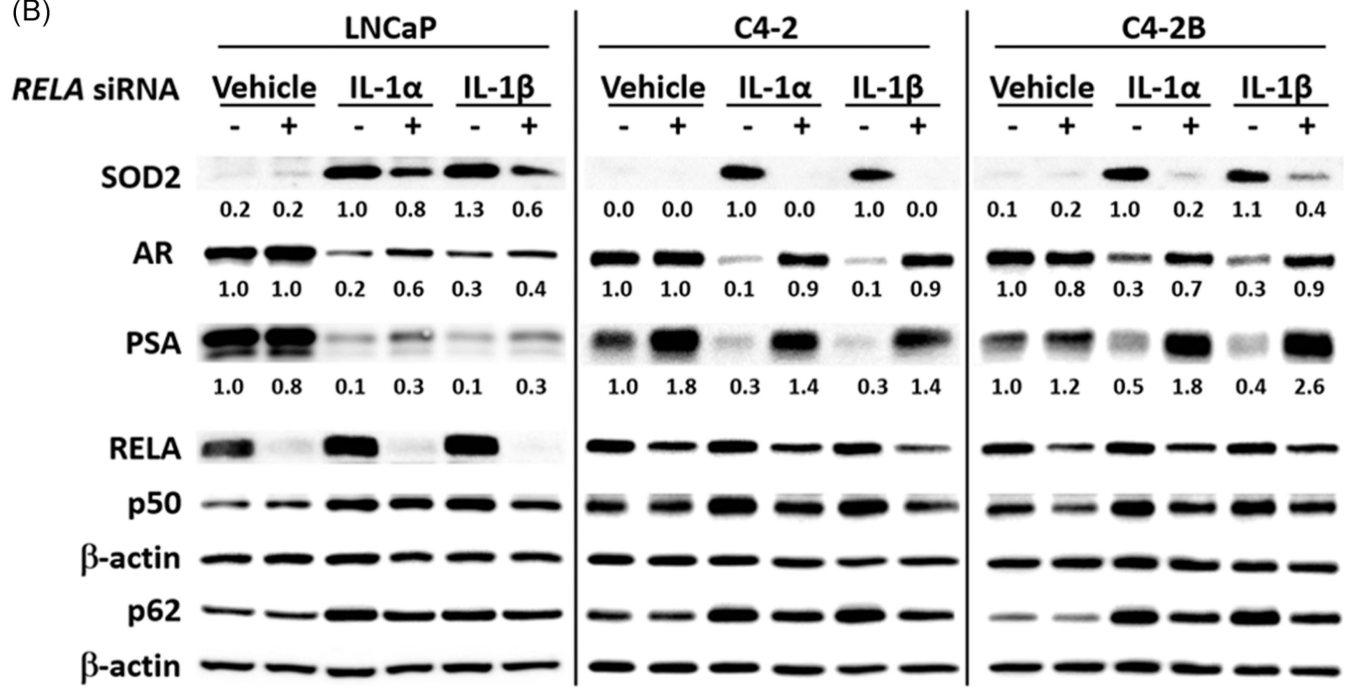

FIGURE 3.

RELA mediates IL-1 repression of AR. A, RT-qPCR and B, Western blot analysis and densitometry were performed for LNCaP, C4-2, and C4-2B cells transfected with $70 \mathrm{nM}$ of nontargeting or RELA siRNA (Dharmacon) for 1 day followed by treatment with vehicle control (Veh), IL-1a, IL-1 $\beta$ for 2 days. LNCaP cells were treated with $0.5 \mathrm{ng} / \mathrm{mL} \mathrm{IL-1,} \mathrm{and}$ C4-2 and C4-2B cells were treated with $25 \mathrm{ng} / \mathrm{mL}$ IL-1. RELA siRNA attenuates IL-1 downregulation of AR and PSA mRNA and protein, and attenuates IL-1 upregulation of SOD2 mRNA and protein. mRNA fold change is normalized to the vehicle control. Error 
bars indicate $\pm \mathrm{SD}$ of three biological replicates; $* P \leq .05, * * P \leq .005, * * * P \leq .0005$. AR, androgen receptor; IL, interleukin; mRNA, messenger RNA; PSA, prostate-specific antigen; RT-qPCR, reverse-transcription quantitative polymerase chain reaction; SD, standard deviation; siRNA, small interfering RNA; SOD2, superoxide dismutase 2 
(A)
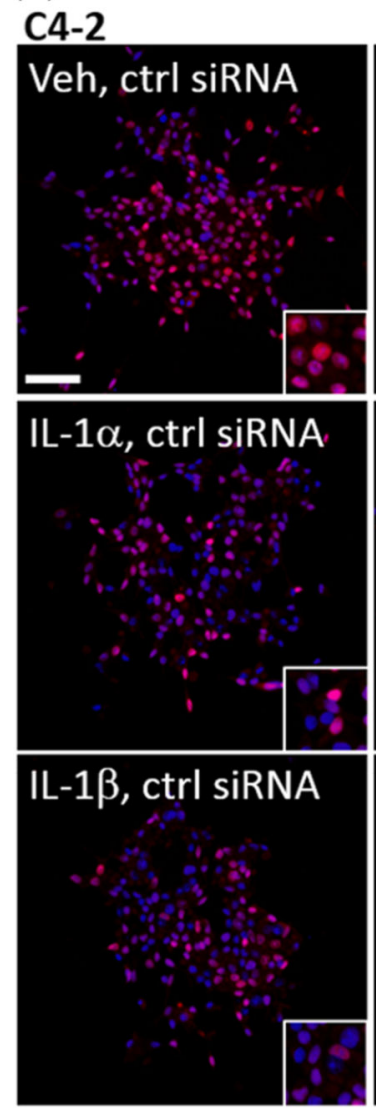

(B) 1.2

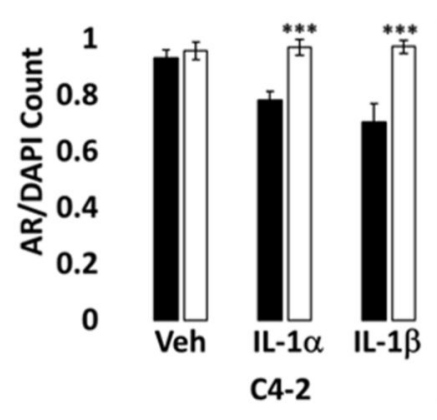

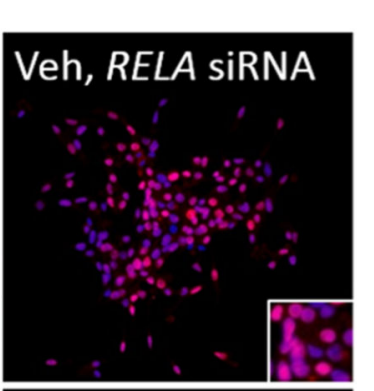
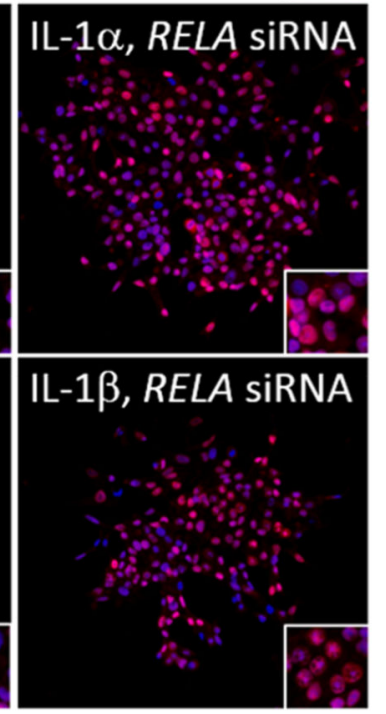

RELA SIRNA

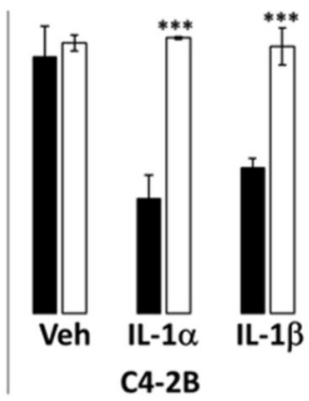

C4-2B
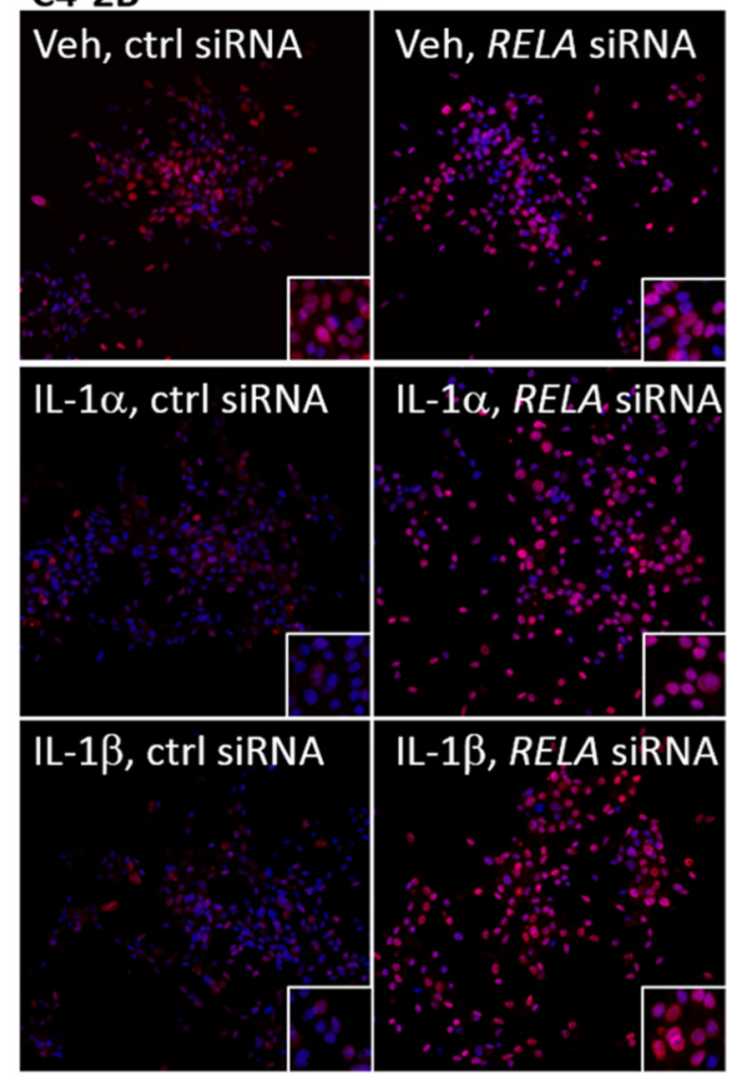

FIGURE 4 .

RELA siRNA restores nuclear AR accumulation in IL-1-treated PCa cells. C4-2 and C4-2B cells transfected with $70 \mathrm{nM}$ of nontargeting or RELA siRNA (Dharmacon) for 1 day followed by treatment with vehicle control (Veh), $25 \mathrm{ng} / \mathrm{mL}$ IL-1a, or $25 \mathrm{ng} / \mathrm{mL} \mathrm{IL-} 1 \beta$ for 2 days. A, Cells were fixed and immunostained for AR (Texas Red) and cell nuclei (DAPI, blue) and imaged at $\times 20$ magnification. AR/DAPI merge images are shown for C4-2 (left) and $\mathrm{C} 4-2 \mathrm{~B}$ (right). $\mathrm{B}$, The ratio (AR/DAPI) of the number of cells accumulating AR to the number of DAPI-stained cells was calculated for five microscopy fields at $\times 10$ magnification, $n>300$ cells per field. AR/DAPI ratio was normalized to vehicle control siRNA. RELA siRNA restores AR nuclear accumulation in IL-1-treated cells. Error bars indicate \pm SD of five microscopy fields; $* * * P \leq .0005$. AR, androgen receptor; DAPI, $4^{\prime}, 6$ - 
diamidino-2-phenylindole; IL, interleukin; SD, standard deviation; siRNA, small interfering RNA [Color figure can be viewed at wileyonlinelibrary.com] 

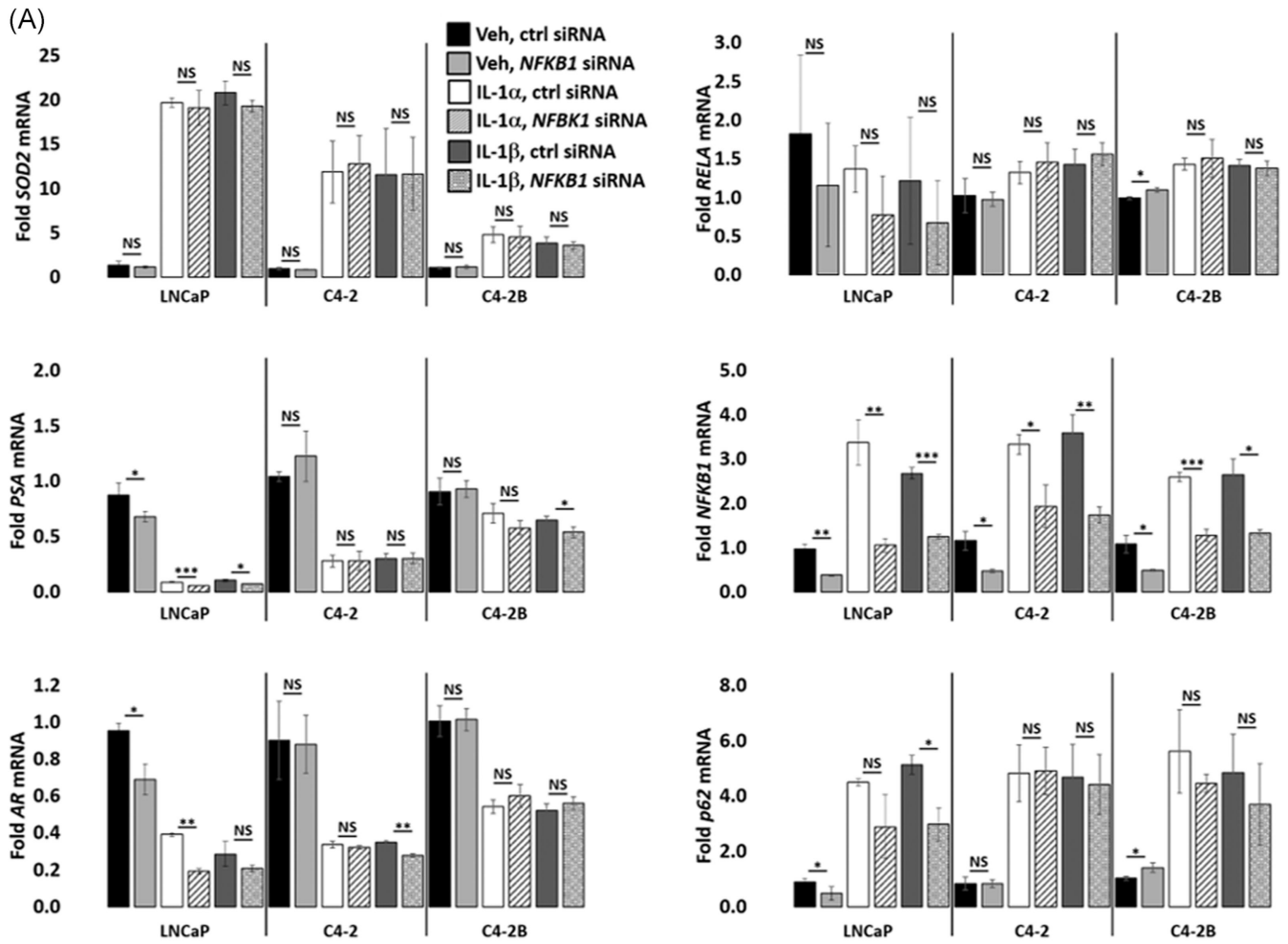

(B)
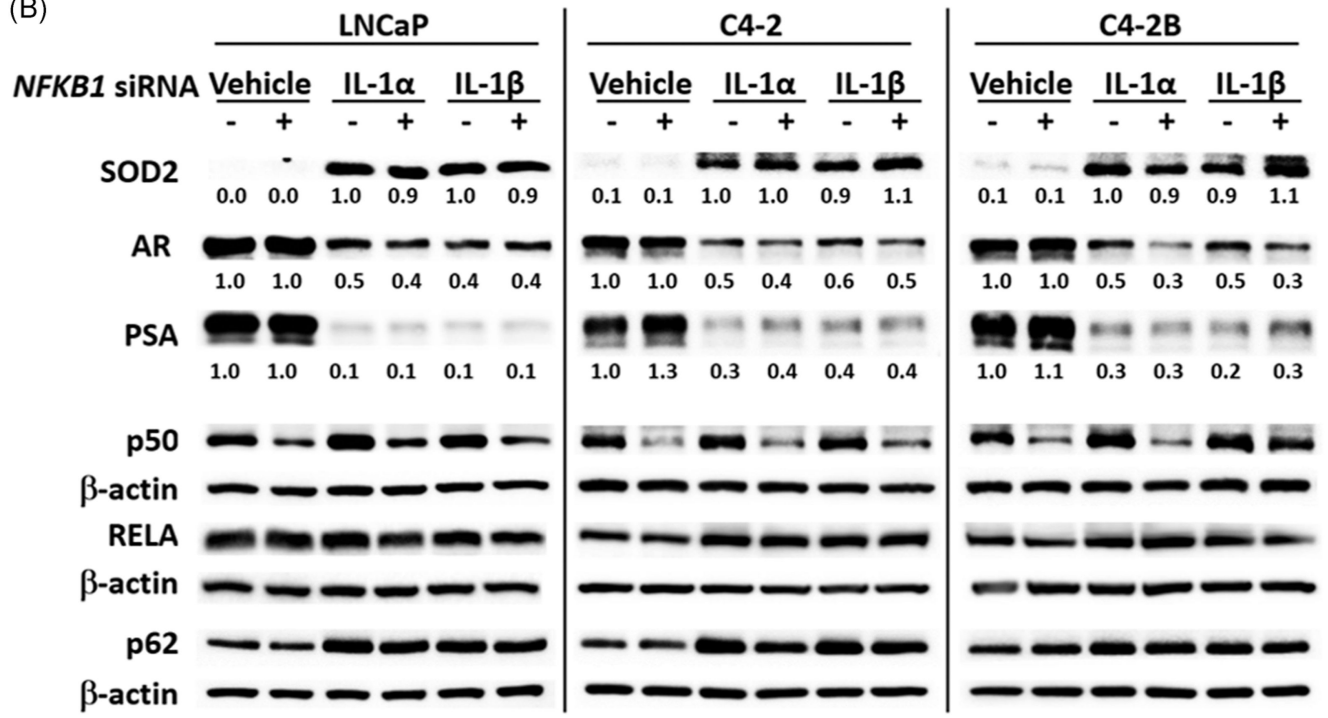

FIGURE 5.

NFKB1(p50) does not mediate IL-1 repression of AR. A, RT-qPCR and B, Western blot analysis and densitometry were performed for $\mathrm{LNCaP}, \mathrm{C} 4-2$, and $\mathrm{C} 4-2 \mathrm{~B}$ cells transfected with $70 \mathrm{nM}$ of nontargeting or NFKB1 siRNA for 1 day followed by treatment with vehicle control (Veh), IL-1a, IL-1 $\beta$ for 2 days. LNCaP cells were treated with $0.5 \mathrm{ng} / \mathrm{mL}$ IL-1 and C4-2 and C4-2B cells were treated with $25 \mathrm{ng} / \mathrm{mL}$ IL-1. NFKB1 siRNA does not attenuate IL-1 downregulation of AR and PSA mRNA and protein, nor does it attenuate IL-1 upregulation of SOD2 mRNA and protein. mRNA fold change is normalized to the vehicle 
control. Error bars indicate $\pm \mathrm{SD}$ of three biological replicates; $* P \leq .05$, ** $P \leq .005$, *** $P \leq$. 0005. AR, androgen receptor; IL, interleukin; mRNA, messenger RNA; PSA, prostatespecific antigen; RT-qPCR, reverse-transcription quantitative polymerase chain reaction; siRNA, small interfering RNA; SOD2, superoxide dismutase 2; SD, standard deviation 
(A) $\square$ Veh, ctrl siRna $\square \mathrm{lL}-1 \alpha$, ctrl siRNA $\square \mathrm{lL}-1 \beta$, ctrl siRNA
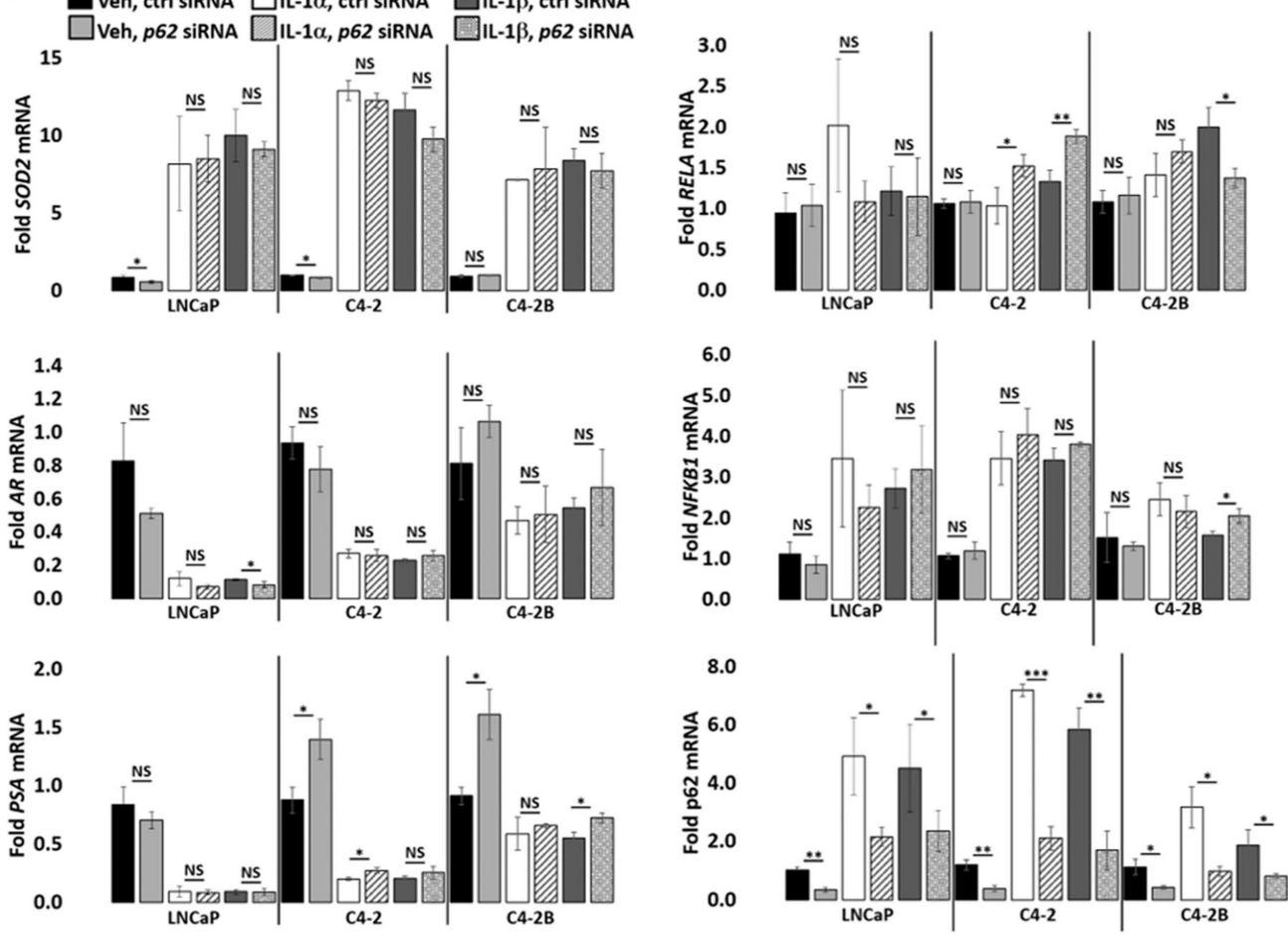

(B)
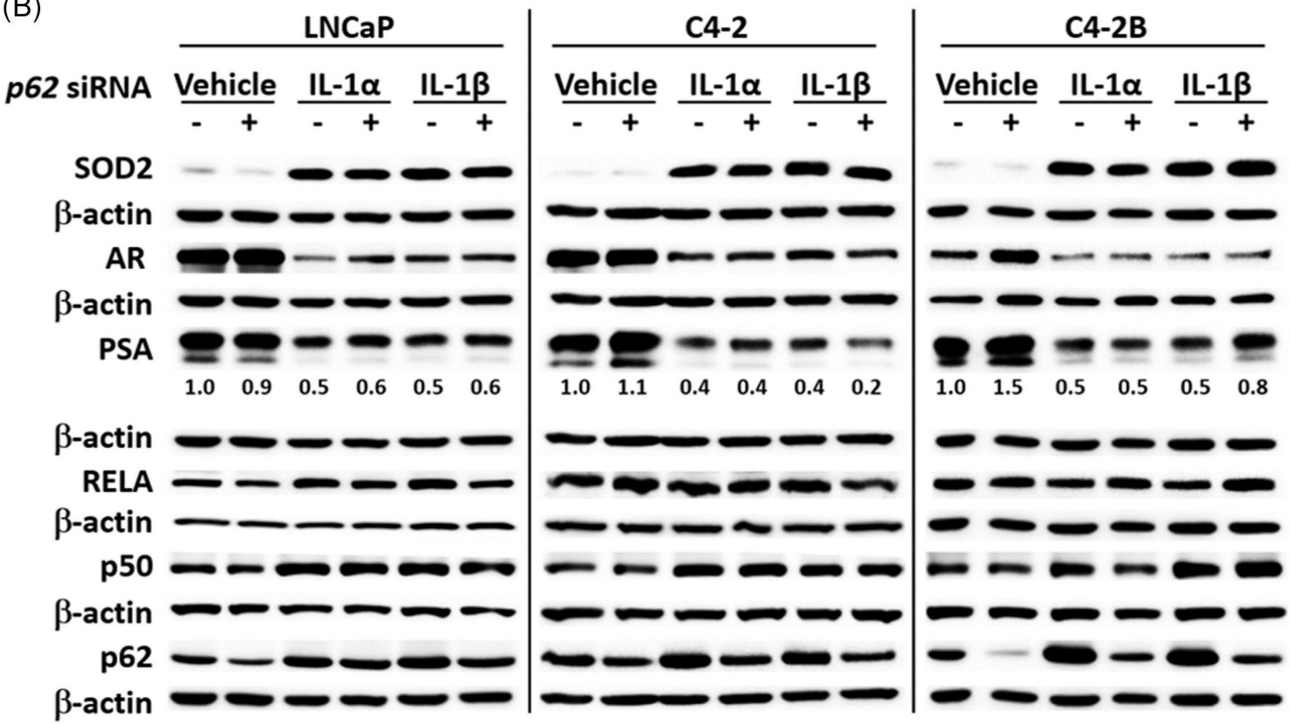

FIGURE 6.

p62 does not mediate IL-1 repression of AR. A, RT-qPCR and B, Western blot analysis and densitometry were performed for LNCaP, C4-2, and C4-2B cells transfected with $70 \mathrm{nM}$ of nontargeting or p62 siRNA for 1 day followed by treatment with vehicle control (Veh), IL-1a, IL-1 $\beta$ for 2 days. LNCaP cells were treated with $0.5 \mathrm{ng} / \mathrm{mL} \mathrm{IL-1}$ and C4- 2 and C4-2B cells were treated with $25 \mathrm{ng} / \mathrm{mL}$ IL-1. p62 siRNA does not attenuate IL-1 downregulation of AR and PSA mRNA and protein, nor does it attenuate IL-1 upregulation of SOD2 mRNA and protein. p62 siRNA significantly upregulates $P S A$ mRNA in C4-2 and 
C4-2B cells under control growth conditions. mRNA fold change is normalized to the vehicle control. Error bars indicate $\pm \mathrm{SD}$ of three biological replicates; $* P \leq .05$, $* * P \leq .005$, $* * * P \leq .0005$. AR, androgen receptor; IL, interleukin; mRNA, messenger RNA; PSA, prostate-specific antigen; RT-qPCR, reverse-transcription quantitative polymerase chain reaction; SD, standard deviation; siRNA, small interfering RNA; SOD2, superoxide dismutase 2 